\title{
Stratospheric water vapor increases over the past half-century
}

\author{
K.H.Rosenlof ${ }^{1}$, S.J.Oltmans ${ }^{2}$, D. Kley ${ }^{3}$, J.M. Russell $\Pi^{4}{ }^{4}$, E-W.Chiou ${ }^{5}$, W.P.Chu ${ }^{6}$, D.G. Johnson ${ }^{7}$, \\ K.K. Kelly ${ }^{1}$, H.A Michelsen ${ }^{8}$, G.E. Nedoluha ${ }^{9}$, E.E. Remsberg ${ }^{6}$, G.C. Toon ${ }^{10}$, M.P.McCormick ${ }^{4}$
}

\begin{abstract}
Ten data sets covering the period 1954-2000 are analyzed to show a $1 \% / y r$ increase in stratospheric water vapor. The trend has persisted for at least 45 years, hence is unlikely the result of a single event, but rather indicative of long-term climate change. A long-term change in the transport of water vapor into the stratosphere is the most probable cause.
\end{abstract}

\section{Introduction}

Determining whether long-term increases in stratospheric water vapor have occurred is important given its radiative [Forster and Shine, 1999] and chemical [Evans et al., 1998; Tabazadeh et al, 2000] significance. The NOAA Climate Monitoring and Diagnostics Laboratory (CMDL) frostpoint hygrometer provides the only continuous multi-decade water vapor record available; over a 20 year period it shows an increase in stratospheric water vapor at Boulder, CO $\left(40^{\circ} \mathrm{N}\right)$ of $\sim 1 \% / \mathrm{yr}(0.05 \mathrm{ppmv} / \mathrm{yr})$ [Oltmans et al., 2000]. Water vapor increases have also been documented from the Atmospheric Trace Molecule Spectroscopy (ATMOS) instrument [Michelsen et al., 2000], from combined multiple in situ measurements [Engel et al., 1996], and from the Halogen Occultation Experiment (HALOE) [Nedoluha et al., 1998; Smith et al., 2000]. Prior work has concentrated on data from the past two decades. Estimates of long-term changes in lower stratospheric water vapor from older in situ data are published [Mastenbrook and Olmans, 1983; Harries, 1976; Cluley and Oliver, 1978], but have been largely ignored in the recent literature. Here, ten stratospheric water vapor data sets are combined to show that increases in stratospheric water vapor have persisted since the mid-1950s.

To examine trends of $\sim 1 \% / \mathrm{yr}$, a long-term data set with complete seasonal coverage from a stable instrument is needed. The large amplitude seasonal cycle in stratospheric entry-level water complicates matters in that incomplete sampling can bias trend estimates. Several data sets taken using assorted techniques are available; the aggregate covers 45 years. Comparisons of coincidences of recent measurements agree to within $10 \%$ [Kley et al., 2000], yet even that agreement does not allow combining data sets to extract a $1 \% / y r$ trend. Instead, longterm changes for individual instruments are estimated and compared. Multi-year time series of Northern Hemisphere (NH) midlatitude water vapor data are available from the instruments listed in Table 1. Extensive spatial coverage from the satellite-borne HALOE is available since 1992. HALOE data allow verification that trends estimated from individual point measurements are valid globally.

${ }^{1}$ NOAA Aeronomy Laboratory, Boulder, CO.

2NOAA Climate Monitoring and Diagnostics Laboratory, Boulder, $\mathrm{CO}$.

${ }^{3}$ Forschungszentrum, Jülich, Germany.

${ }^{4}$ Hampton University, Hampton, VA.

${ }^{5} \mathrm{SAIC}$, Hampton, VA

'NASA/Langley Research Center, Hampton, VA.

${ }^{7}$ Harvard-Smithsonian Center for Astrophysics, Cambridge, MA, now at NASA/Langley Research Center, Hampton, VA.

${ }^{8}$ Sandia National Laboratories, Livermore, CA.

Naval Research Laboratory, Washington, D.C.

${ }^{10}$ Jet Propulsion Laboratory, Pasadena, CA.

Copyright 2001 by the American Geophysical Union.

Paper number 2000GL012502.

0094-8276/01/2000GL012502\$05.00

\section{Data Analysis}

Fig. 1 shows CMDL and HALOE data at $21 \mathrm{hPa}$. This level is well above where the seasonal cycle impacts the analysis, thereby avoiding sampling biases. A regression analysis including linear, 27 month quasi-biennial, annual, and semiannual terms for the period Jan. 1992 through Mar. 2000 yields a linear change ( $1 \sigma$ uncertainty) of +0.029 $(0.01) \mathrm{ppmv} / \mathrm{yr}$ for the HALOE series and $+0.030(0.03) \mathrm{ppmv} / \mathrm{yr}$ for the CMDL series subset. The corresponding HALOE $\mathrm{CH}_{4}$ trend at this level is $+0.003(0.002) \mathrm{ppmv} / \mathrm{yr}$. This trend is comparable to the surface $\mathrm{CH}_{4}$ increase over this time period [Dlugokencky et al., 1998], indicating that a change in the length of time air at this location has resided in the stratosphere is not the cause of the $\mathrm{H}_{2} \mathrm{O}$ increase.

To show that $\mathrm{NH}$ midlatitude trends are globally representative, estimates were made for different latitude subsets. HALOE $\mathrm{H}_{2} \mathrm{O}$ measurements between $50^{\circ} \mathrm{N}$ and $50^{\circ} \mathrm{S}$ in the $0.98-1.18 \mathrm{ppmv} \mathrm{CH}_{4}$ bin were selected. This bin corresponds to the average $\mathrm{CH}_{4}$ value of 1.08 (0.1) ppmv for the HALOE points shown in Fig 1. Such filtering samples air of approximately the same stratospheric residence time, allowing compilation of a global time series in the presence of residence time spatial gradients. The range, shown in Table $2,(+0.031$ to $+0.035 \mathrm{ppmv} / \mathrm{yr}$ ) is sufficiently close to the HALOE $35^{\circ}-45^{\circ} \mathrm{N}, 95^{\circ}-$ $115^{\circ} \mathrm{W}, 21.5 \mathrm{hPa}$ estimate of $+0.029 \mathrm{ppmv} / \mathrm{yr}$ to establish that the midlatitude trends are globally representative. The HALOE results in Table 2 have much smaller uncertainties than those presented in Fig. 1 because of the greater number of points included in the regression.

Increases over the past 20 years have not been monotonic. Fig. 2 shows the CMDL rate of change at $21.5 \mathrm{hPa}$ deduced from computing the linear change term with a sliding 4-year period. The average over the entire period is $+0.03 \mathrm{ppmv} / \mathrm{yr}$, however, there are periods with negative rates of change that make up only $40 \%$ of the record, but dominate since 1996. The HALOE data also give a negative trend sinœe 1996 and a similar period is seen in the CMDL record centered around 1985. It is clear that long-term changes in stratospheric water vapor cannot be inferred from relatively short data records, hence, other data were examined to determine the sign of the long-term trend.

Data used are listed in Table 1. With the exception of HALOE, ATMOS, and the Stratospheric Aerosol and Gas Experiment (SAGE) II, data are limited to NH midlatitudes. SAGE II trends in the lower stratosphere are strongly affected by volcanic aerosol contamination [Kley et al., 2000], but appear to be valid above $15 \mathrm{hPa}$. The Naval Research Laboratory (NRL) instrument was redesigned in 1977, therefore NRL data later than 1976 are ignored here. Altitude coverage varies with Water Vapor Millimeter-wave Spectrometer (WVMS) measurements only above $40 \mathrm{~km}$ and Aeronomy Laboratory (AL) Lyman- $\alpha$ and United Kingdom Meteorology Office Meteorological Research Flights (MRF) frostpoint measurements limited to levels below $50 \mathrm{hPa}$ and 110 $\mathrm{hPa}$ respectively. Other data cover the bulk of stratospheric altitudes. All data were available in digital form excpt the MRF measurements. These were extracted from published tables [Bannon et al, 1952; Cluley and Oliver, 1978; Heliwell et al., 1957; Murgatroyd et al, 1955; Foot, 1984] with a correction for the oldest measurements applied [Oliver and Cluley, 1978]. The analysis is restricted to data collected with the final version of the instrument starting in 1954. All data were filtered by tropopause height. This filtering only affects midlatitude measurements below $\sim 100 \mathrm{hPa}$, and eliminates less than $15 \%$ of the original data

Upper stratospheric NH midlatitude data are shown in Fig. 3. Except from mid-1993 to mid-1994, SAGE II and HALOE variations are in 
Table 1. Datasets Used in $\mathrm{H}_{2} \mathrm{O}$ Trend Analysis.

\begin{tabular}{ccccc}
\hline Instrument & Technique & Platform & Analysis Period & Reference \\
\hline MRF & Frostpoint hygrometry & Aircraft & $1954-1980$ & Cluley and Oltver [1978] \\
NRL & Frostpoint hygrometry & Balloon & $1964-1976$ & Mastenbrook and Oltmans [1983] \\
AL Lyman- $\alpha$ & Lyman- $\alpha$ fluorescence & Balloon \& aircraft & $1978-1998$ & Kelly et al. $[1990]$ \\
CMDL & Frostpoint hygrometry & Balloon & $1980-2000$ & Oltmans et al. $[2000]$ \\
ATMOS & FTIR spectrometry & Space Shuttle & $1985-1994$ & Mchelsen et al. [2000] \\
WVMS & Millimeter-wave spectrometry & Ground & $1992-1997$ & Nedoluha et al. [1998] \\
FIRS-2 & FIR spectrometry & Balloon & $1989-1997$ & Johnson et al. [1999] \\
MkIV & FTIR spectrometry & Balloon & $1990-1997$ & Toon $[1991]$ \\
HALOE V19 & Solar occultation & Satellite & $1992-2000$ & Evans et al. $[1998]$ \\
SAGE-II V6 & Solar occultation & Satellite & $1985-2000$ & Rind et al. [1993] \\
\hline
\end{tabular}

aAdditional information on the newV6 release of SAGE II data is available at http/:www-sage2.larc.nasa.gov.

good agreement (Fig. 3a), although there is a $\sim 10 \%$ offset $(0.5 \mathrm{ppmv})$ in absolute magnitude [Johnson et al., 1999]. The 1993-1994 period was removed from the SAGE II trend calculation. Both data sets give positive trends, with largest increases from 1992 through $1997(-0.04$ ppmv/yr), and little net change between 1985 and 1991. Altitude coverage only allows WVMS to be compared with HALOE (Fig. 3b). Both WVMS and HALOE show large increases between 1993 and 1997 ; the net increase for the entire HALOE record is $\sim 0.05 \mathrm{ppmv} / \mathrm{yr}$.

Because of the varying latitudinal and seasonal coverage of the balloon and shuttle instruments, they are compared relative to $\mathrm{N}_{2} \mathrm{O}$, a long-lived tracer measured by the ATMOS, Jet Propulsion Laboratory MkIV, and Harvard-Smithsonian Center for Astrophysics Far-infrared Spectrometer (FIRS-2) instruments. This filtering samples air of approximately the same average stratospheric residence time, allowing a time series to be constructed with data from varying latitudes and seasons. Fig. 4 shows these data plotted for the $25-50 \mathrm{ppbv} \mathrm{N}_{2} \mathrm{O}$ bin, corresponding to $\sim 5-10$ $\mathrm{hPa}$. Increases with time are seen in all three instnuments; this increase has been previously documented for ATMOS. Because of sparse temporal resolution and the fact that $\mathrm{N}_{2} \mathrm{O}$ binning effectively removes seasonal cycle transport effects, only a linear term is included in the regression. For the data shown in Fig. 4, trends range from +0.06 to +0.12 ppmv/yr.

In situ data in the lower stratosphere are plotted in Fig. 5; trend results are annotated on the figure. NRL, CMDL, and AL Lyman- $\alpha$ data are available in the $60-70 \mathrm{hPa}$ layer (Fig. 5a). Estimated trends are positive, varying between +0.03 and +0.08 ppmv/yr. In the 140-160 hPa layer, MRF aircraft frostpoint measurements also exist (Fig. 5b). All data show increases over time with linear trends ranging from +0.03 to $+0.11 \mathrm{ppmv} / \mathrm{yr}$.

A compilation of the estimated trends as a function of altitude for all the data sets is shown in Fig. 6, with trends for NH midlatitude sites

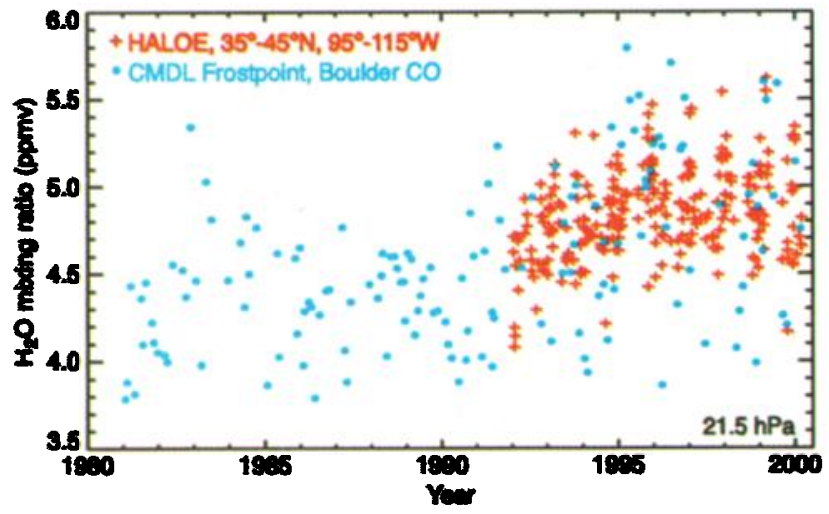

Figure 1. HALOE and CMDL water vapor at $21.5 \mathrm{hPa}$ over Boulder, CO $\left(400^{\circ} \mathrm{N}, 105^{\circ} \mathrm{W}\right)$. HALOE data are from $35^{\circ}-45^{\circ} \mathrm{N}$ and $95^{\circ}-115^{\circ} \mathrm{W}$. Average differences are $\sim 5 \%$, however, trends are similar with a HALOE trend of $+0.029 \mathrm{ppmv} / \mathrm{yr}$ and a CMDL trend of $+0.030 \mathrm{ppmv} / \mathrm{yr}$.
Table 2. January 1992 to March 2000 HALOE $\mathrm{H}_{2} \mathrm{O}$ Trends for the 0.98-1.18 $\mathrm{CH}_{4} \mathrm{Bin}$

\begin{tabular}{ccc}
\hline Location & $\begin{array}{c}\text { Linear Trend } \\
(\mathrm{ppmv} / \mathrm{yr})\end{array}$ & $1 \sigma$ Uncertainty \\
\hline Southern Hemisphere & +0.031 & 0.0004 \\
Northern Hemisphere & +0.033 & 0.0004 \\
Tropics & +0.035 & 0.0006 \\
Global & +0.033 & 0.0003 \\
\hline
\end{tabular}

(Fig. 6a) and trends deduced from $\mathrm{N}_{2} \mathrm{O}$-binned data (Fig. 6b). Nearly all the trends are positive, with an average of $+0.045 \mathrm{ppmv} / \mathrm{yr}$. Differences between trends deduced from various periods do not indicate errors, but demonstrate that the long-term change is not well modeled by a simple linear term (Fig. 2). The net result is that all the data indicate increases in time, and the cumulative increase over 45 years is a large fraction of the average stratospheric water content.

\section{Discussion and Summary}

The magnitude of the average change estimated yields a $2 \mathrm{ppmv}$ increase in stratospheric water vapor since the mid-1950s. This increase is substantial, given current stratospheric water vapor values of 4-6 ppmv. The reason for such an increase is not understood. $\mathrm{CH}_{4}$ destruction is a water source in the stratosphere, yielding approximately two water molecules for each methane molecule destroyed. Tropospheric $\mathrm{CH}_{4}$ increases covering the industrial age are well documented, amounting to a change of -0.55 ppmv over the past 45 years [Etheridge et al., 1998]. This $\mathrm{CH}_{4}$ increase should produce a stratospheric water vapor increase of at most

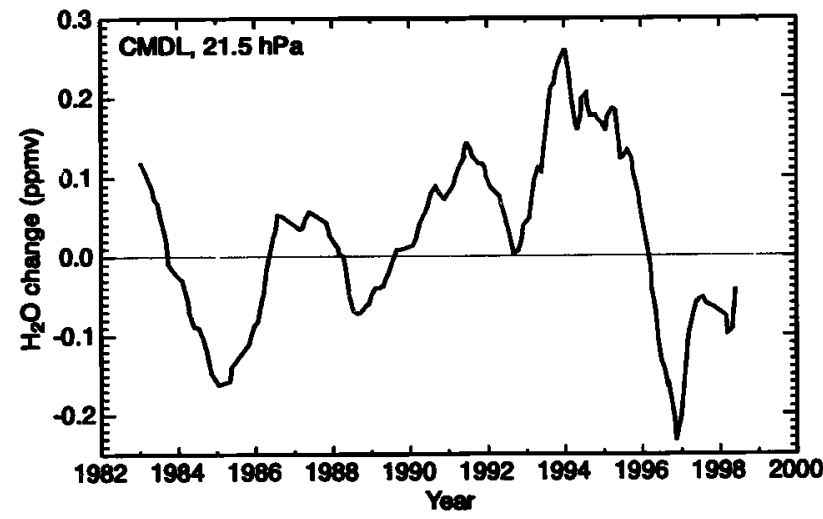

Figure 2. 4-year sliding linear rate of change for CMDL water vapor measurements at $21.5 \mathrm{hPa}$ computed via a regression analysis for 4-year periods centered on the plotted values. 

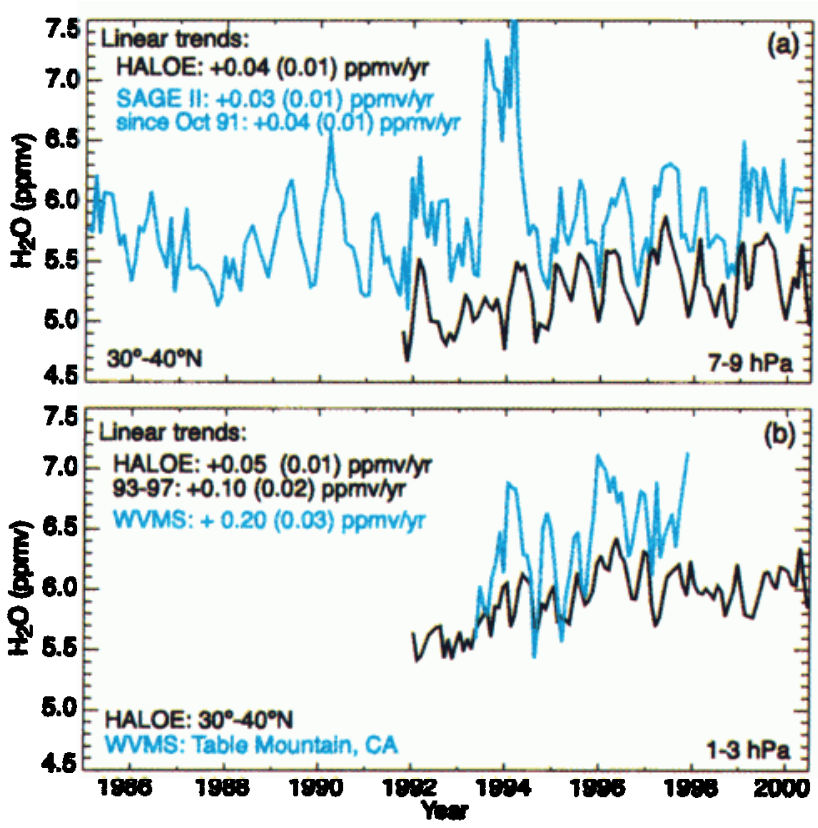

Figure 3. Monthly averaged NH midlatitude upper stratospheric water vapor. (a) HALOE (black) and SAGE II (turquoise) at $30^{\circ}$ $40^{\circ} \mathrm{N}$ and 7-9 hPa (b) HALOE (black) and WVMS (turquoise) at 1$3 \mathrm{hPa}$. HALOE and SAGE II data are averaged from $30^{\circ}-40^{\circ} \mathrm{N}$, WVMS data are from Table Mountain, CA. Linear trend (1 $\sigma$ uncertainty) results are annotated on the panels.

$\sim 1.1$ ppmv, approximately half of that estimated here. Large changes are apparent in the lowermost NH midlatitude stratosphere below the 100 $\mathrm{hPa}$ level (Fig. 6a) where $\mathrm{CH}_{4}$ oxidation is far from complete, indicating other mechanisms must also be important. There is vertical structure in the trends shown in Fig. $6 \mathrm{a}$, with a relative minimum in the $50-100 \mathrm{hPa}$ layer. Examination of HALOE trends (not shown) confirms this feature was present globally over the past decade. That this minimum exists indicates that the reason for trends in the midlatitude lowermost stratosphere (below $100 \mathrm{hPa}$ ) likely differs from that above $50 \mathrm{hPa}$

Aircraft emissions in the lower stratosphere have increased over this period, but the effect at lower stratosphere midlatitudes is estimated to be only $+0.018 \% / y r$ [Danilin et al., 1998], much smaller than the observed $1 \% / y r$ increase. It has been suggested that changes in the tropical entry value of water vapor contribute to the observed increase [Nedoluha et al., 1998; Oltmans and Hofmann, 1995]. However, decreasing tropical tropopause temperatures have been noted over the past 20 years [Simmons et al., 1999]. This should have decreased stratospheric water if the tropical cold trap, which assumes air crosses

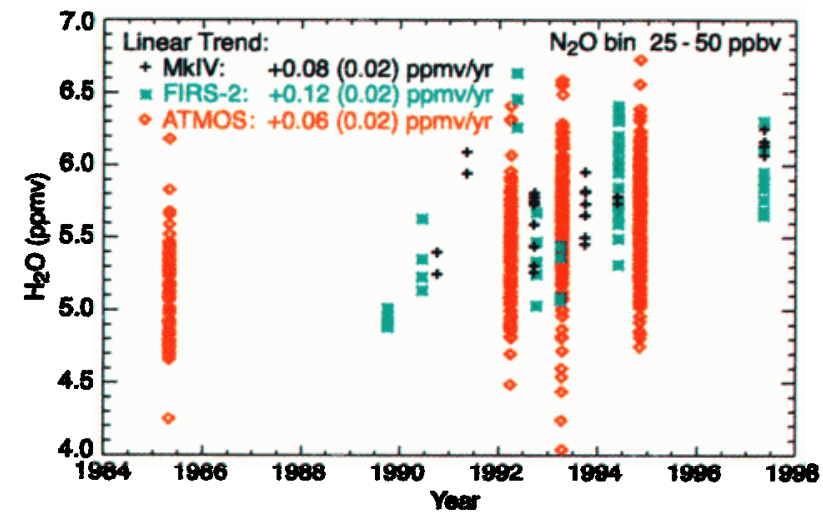

Figure 4. Water vapor time series from MkIV, FIRS-2, and ATMOS in the 25-50 ppbv $\mathrm{N}_{2} \mathrm{O}$ bin, representative of the upper stratosphere at pressures from 5-10 hPa. Estimated linear trends ( $1 \sigma$ uncertainties) are annotated on the plot.
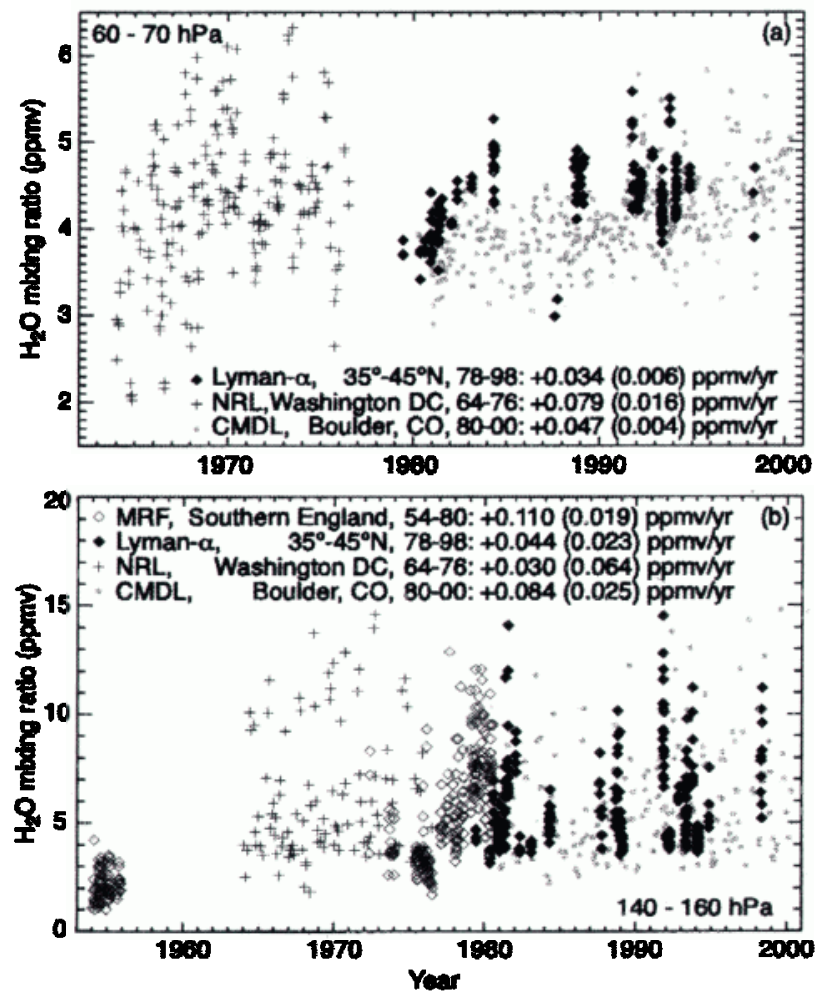

Figure 5. Time series of lower stratospheric water vapor from in situ measurements at NH midlatitudes for (a) $60-70 \mathrm{hPa}(440-500 \mathrm{~K})$ and (b) $140-160 \mathrm{hPa}(360-390 \mathrm{~K})$. Data were filtered by tropopause height. The linear trend ( $1 \sigma$ uncertainty) results are annotated on the plot. For the CMDL and NRL data, the full regression analysis was done. Sparse temporal resolution permitted only a linear term in the MRF and AL Lyman- $\alpha$ regression analysis.
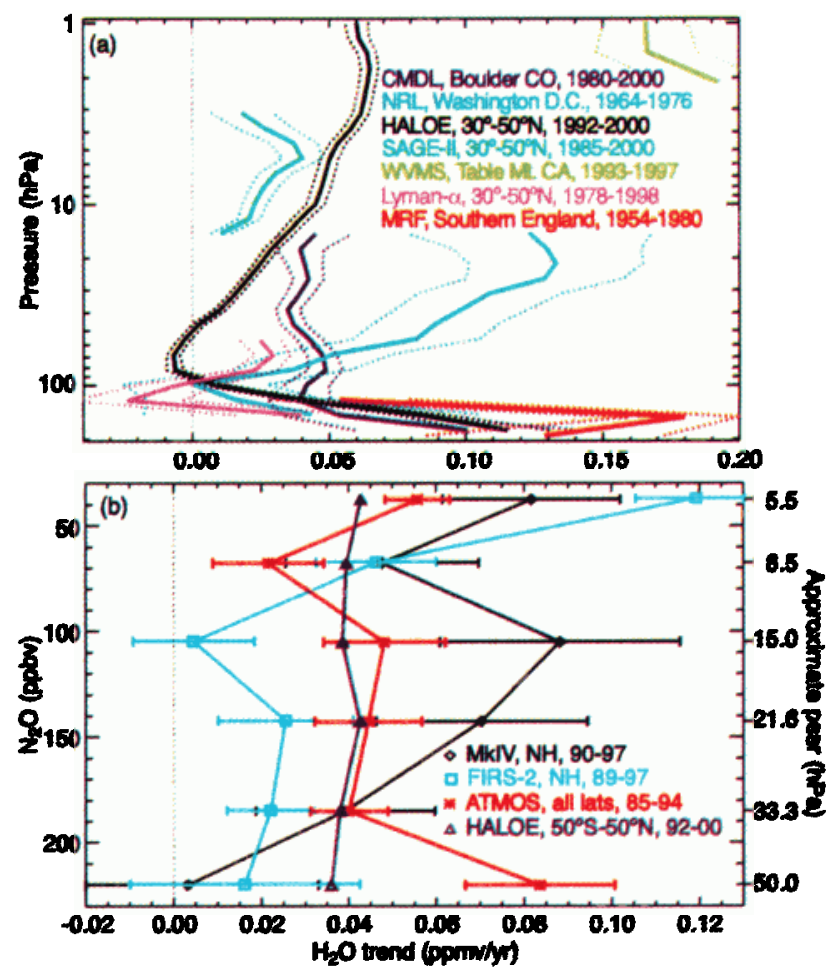

Figure 6. Vertical profiles of the estimated linear trends for all data sets. Colors and valid years are annotated on the panels. (a) Trends for $30^{\circ}-50^{\circ} \mathrm{N}$. (b) Trends from the balloon and shuttle instruments with variable latitude sampling. Data were binned by $\mathrm{N}_{2} \mathrm{O}$; approximate pressure is given on the right axis. $\mathrm{A} \mathrm{CH}_{4}: \mathrm{N}_{2} \mathrm{O}$ relationship from the MkIV instrument was used to convert $\mathrm{CH}_{4}$ binned HALOE trends to the $\mathrm{N}_{2} \mathrm{O}$ axis. In both panels, trends are shown with a solid line; $1 \sigma$ uncertainties are given by dashed lines in (a) and horizontal bars in (b). 
the tropical tropopause at the saturation mixing ratio, was the only controlling factor. This explanation is thus invalid.

Because the water increase is of long duration, it is not possible to attribute it to a single event. Large-scale changes in stratospheric circulation and troposphere-stratosphere exchange are possible causes. If longterm changes in the distribution of radiatively active trace species have increased the effective stratospheric residence time through a slowing of the circulation, $\mathrm{CH}_{4}$ oxidation will have longer to occur, producing longterm water vapor increases. However, since water increases are evident even in data binned by $\mathrm{CH}_{4}$, this process cannot be the sole mechanism responsible for the observed trends.

A change in the atmospheric circulation that increases the amount of water entering the stratosphere by either increasing the relative fraction of air entering during the tropical tropopause warm season (NH summer) or widening the region of tropical rising motion across the tropopause to include warmer temperatures [Zhou et al., 2001] may explain the observed long-term increase in stratospheric water. The increase in tropical sea surface temperatures noted since 1945 [Cane et al., 1997] lends credence to the idea that transport into the stratosphere through the tropical tropopause has changed over the same time even though the water vapor increase cannot be directly related to trends in tropical tropopause temperature. In the lowermost stratosphere, there is also evidence from observations of ozone minima [Reid et al., 2000] that transport through the tropopause break has increased over the past 25 years. Such a change would increase water in the lowermost stratosphere, in that a greater fraction of the air present would not have passed through the tropical cold trap.

Although the mechanism for the observed stratospheric water increase is not thoroughly understood, the ten data sets examined here collectively indicate that a trend of $\sim+0.045 \mathrm{ppmv} / \mathrm{yr}$ has persisted for nearly a half-century. It is likely that different mechanisms are responsible for increases in separate layers in the stratosphere. Additional theoretical studies and continued monitoring of $\mathrm{H}_{2} \mathrm{O}, \mathrm{CH}_{4}$, and temperature between the tropopause and $10 \mathrm{hPa}$ on a global scale, ideally of high vertical and horizontal resolution, are needed to resolve this issue.

Acknowledgements. Larry Gordley and David Fahey provided helpful comments on an earlier version of this manuscript.

\section{References}

Bannon, JK, et al, Humidity of the upper troposphere and lower stratosphere over Southem England, in Geophysical Memoirs, pp. 36, UK. Met Office, London, 1952. Cane, M, etal., Twentieth-century sea surface temperature, Science, 275, 957-960, 1997.

Cluley, AP., and MJ. Oliver, Aircraft measurements of humidity in the low stratosphere over Southem England 1972-1976, Q. J. R Meteorol. Soc., 104, 511526, 1978.

Danilin, M.Y., et al., Aviation fuel tracer simulation: Model intercomparison and implications, Geophys. Res. Lett., 25, 3947-3950, 1998.

Dlugokencky, E.J., et al., Continuing decline in the growth rate of the atmospheric methane burden, Nature, 393, 447-450, 1998.

Engel, A., et al., The total hydrogen budget in the arctic winter stratosphere during the European arctic stratospheric ozone experiment, $J$. Geophys. Res., 101, 14495-14503, 1996.

Etheridge, D.M., et al., Atmospheric methane between 1000 A.D. and present: Evidence of anthropogenic emissions and climate variability, J. Geophys. Res., 103, 15979-15993, 1998.
Evans, S.J., et al., Trends in stratospheric humidity and the sensitivity of ozone to these trends, J. Geophys. Res., 103, 8715-8725, 1998.

Foot J.S., Aircraft measurements of the humidity in the lower stratosphere from 1977 to 1980 between $45^{\circ} \mathrm{N}$ and $65^{\circ} \mathrm{N}, Q . J . R$ Metecol. Soc., $110,303-319,1984$.

Forster, P.M. de F., and K.P. Shine, Stratospheric water vapour changes as a possible contributor to observed stratospheric cooling., Geophys. Res. Lett., 26, 3309-3312, 1999.

Harries, J.E., The distribution of water vapor in the stratosphere, Rev. Geophys. Space Phys., 14, 565-575, 1976.

Heliwell, N.C., et al., Some further observations from aircraft of frost point and temperature up to $50,000 \mathrm{ft}, Q . J . R$. Meteorol. Soc., $83,257-262,1957$.

Johnson, D.G., et al., Stratospheric age spectra derived from observations of water vapor and methane, J. Geophys. Res., 104, 21,595-21,602, 1999.

Kelly, K.K., et al., A comparison of ER-2 measurements of stratospheric water vapor between the 1987 Antarctic and 1989 Arctic airborne missions, Geophys. Res. Lett., 17, 465-468, 1990.

Kley, D, et al., SPARC assessment of upper tropospheric and stratospheric water vapour, WCRP - No. 113, WMO/TD-No. 1043, SPARC Report No. 2, 2000.

Mastenbrook, H.J., and S.J. Oltmans, Stratospheric water vapor variability for Washington D.C.Boulder, Co.: 1964-1982, J. Atmos. Sci, 40,2157-2165, 1983.

Michelsen, H.A., et al., Features and trends in Atmospheric Trace Molecule Spectroscopy (ATMOS) version 3 stratospheric water vapor and methane measurements, J. Geophys. Res., I05, 22713-22724, 2000.

Murgatroyd, R.J., et al., Some recent measurements of humidity from aircraft up to heights of about 50,000 $\mathrm{ft}$ over Southern England, $Q . J . R$. Meteorol. Soc., 81, 533-537, 1955.

Nedoluha, G.E., et al., Increases in middle atmospheric water vapor as observed by HALOE and the ground-based water vapor millimeter-wave spectrometer from 1991-1997, J. Geophys. Res., 103, 3531-3542, 1998.

Oliver, MJ., and AP. Cluley, A systematic error in the measurement of frost point using a meteorological office MK 3 hygrometer, Q.J.R Meteorol. Soc., 104, 503-509, 1978.

Oltmans, S.J., and D.J. Hofmann, Increase in lower-stratospheric water vapor at a midlatitude N.H. site from 1981 to 1994 , Nature, 374, 146-149, 1995.

Oltmans, S.J., et al., The increase in stratospheric water vapor from balloonborne, frostpoint hygrometer measurements at Washington, D. C., and Boulder, Colorado, Geophys. Res. Lett., 27, 3453-3456, 2000.

Reid, S.J, et al., On the changing abundance of ozone minima at northern midlatitudes, J. Geophys. Res., 105, 12169-12180, 2000.

Rind, D., et al., Overview of the Stratospheric Aerosol and Gas Experiment II water vapor observations. Method, validation, and data characteristics, $J$. Geophys. Res., 98, 4835-4856, 1993.

Simmons, A.J., et al., Stratospheric water vapor and tropical tropopause temperatures in ECMWF analyses and multi-year simulations, $Q . J . R$ Meteorol. Soc., 125, 353-386, 1999.

Smith, C.A., et al., Seasonal trends in stratospheric water vapour, Geophys. Res. Lett., 27, 1687-1690, 2000.

Tabazadeh, A., et al., Quantifying denitrification and its effect on ozone recovery, Science, 288, 1407-1411, 2000.

Toon, G.C., The JPL MKIV interferometer, Optics and Photonics News, 2, 19-21, 1991.

Zhou, X.-L., et al., The cooling trend of the tropical cold point tropopause temperatures and its implications, J. Geophys. Res., I06, 1511-1522, 2001.

K. K. Kelly and K. H. Rosenlof, NOAA Aeronomy Laboratory, 325

Broadway, Boulder, CO 80305. (e-mail krosenlof@al.noaa.gov). S. J. Oltmans, NOAA CMDL, 325 Broadway, Boulder CO 80305. D. Kley, Forschungszentrum, Jülich, Germany.

M. P. McCormick and J. M. Russell III, Department of Physics, Hampton University, Hampton, VA 23668. E-W Chiou, W. P. Chu, D. J. Johnson, E. E. Remsberg, NASA Langley Research Center, Hampton, VA 23681.

H. A. Michelsen, Sandia National Laboratories, Livermore, CA 94551.

G. E. Nedoluha, Naval Research Laboratory, Washington, D.C. 20375.

G. C. Toon, Jet Propulsion Laboratory, Pasadena, CA 91109.

(Received October 18, 2000; revised January 8, 2001; accepted January 16, 2001.) 